\title{
Isolation, characterization and structural elucidation of bioactive compound in aurora globostellata
}

\begin{abstract}
Marine environment is a repository of many valuable therapeutic substances. Of the different marine biota, the benthic community, Poriferans (Sponges) are goldmine for many pharmaceutical compounds. The sponges were identified using meristic and morphometric characteristics. The sponge species which have confusion in conventional taxonomical study were subjected to $18 \mathrm{~S}$ rRNA genomic sequencing studies. The present study of sponges, the sponge Aurora globostellata was further selected for an in-depth study based on the bioactive potential and quantum of availability. The compound was crystallized and subjected to NMR $\left({ }^{1} \mathrm{H}-\mathrm{NMR},{ }^{13} \mathrm{C}-\mathrm{NMR}, \mathrm{DEPT}-135\right.$, DOSY), HR-MS, IR, UV and fluorescent analysis. The structure of the compound in this fraction was characterized and it was identified as Azasterol glycoside
\end{abstract}

Keywords: aurora globostellata, ${ }^{1} \mathrm{H}-\mathrm{NMR},{ }^{13} \mathrm{C}-\mathrm{NMR}, \mathrm{DEPT}-135$, DOSY), HR-MS, IR, UV spectrometer
Volume I Issue I - 2015

\author{
Chairman K,' Ranjit Singh AJA, ${ }^{2}$ Murugesan \\ $A G^{3}$ \\ 'Department of Microbiology, Kamarajar Govt. Arts College MS \\ University, India \\ 2JP College of Arts and Science, India \\ ${ }^{3}$ Department of Environmental Science, MS University, India
}

Correspondence: Ranjit Singh AJA, the Principal, JP College of Arts and Science, Ayikudi, Tenkasi, Tirunelvei, India, Tel 973-2456506, Email chairmanspkc@gmail.com

Received: April 09, 2015 | Published: October 13, 2015
Abbreviations: NMR, nuclear magnetic resonance analysis; HR-MS, high resolution mass spectrum; UV, ultra violet spectroscopy; IR, infra red spectroscopy; RP, reversed phase

\section{Introduction}

The ocean covers about $70 \%$ of the earth surface providing a diverse living environment for invertebrates. ${ }^{1}$ Therefore, marine natural products will play a major role in drug discovery in the future. The work on marine natural products started 59 years ago when Bergman discovered the novel bioactive Arabino-nucleoside from marine sponge Cryptotethya crypta. ${ }^{2}$ This discovery encouraged natural products chemist to pay attention to marine natural products as important biomedical source. In order to survive in a highly competitive environment, marine invertebrates produce a tremendous diversity of extreme toxic compounds. This has stimulated research groups to screen marine samples in various cytotoxic assays.

Some of the compounds from marine invertebrates initially discovered were either too toxic or not effective in treating diseases for pharmaceutical purposes, but were found to be useful as biological tools or as cosmetic ingredients or as agrochemicals. ${ }^{3}$ The Caribbean gorgonian, Pseudopterogorgia elisabethae, is an example of a source of marine natural product used in the cosmetic industry. The extract from this gorgonian shows anti-inflammatory activity, which nowadays is used as an ingredient in cosmetic skin care products. ${ }^{4}$ Largest groups of marine invertebrates as a source of secondary metabolites are the sponges. The structurally diverse varieties of metabolites have high therapeutic potential to treat human diseases and have made them worthy of research for marine natural chemists. ${ }^{5}$ Natural products isolated from the phylum Porifera account for $50 \%$ of those reported from marine invertebrates. About $98 \%$ of these metabolites are derived from amino acids, Acetogenin, and the Isoprenoid pathway. ${ }^{6}$

There are many classes of alkaloids which were isolated from marine sponges. However, one interesting group is the Bromopyrroleimidazole alkaloids due to its biological activity and structural diversity. About 90 compounds of this class of alkaloids were characterized.?
Marine organisms are rich sources of unconventional steroids. Numerous uncommon steroids have been discovered from a wide variety of marine sources, especially sponges, octocorallias, and echinoderms, since the early 1970 s. ${ }^{8,9}$

Ishibashi et al. ${ }^{9}$ isolated 10 new 7-hydroxysterols having variations on the side chains from a sponge, Topsentia sp. collected in Okinawa. Kobayashi et al. ${ }^{10}$ earlier described the discovery of three new C29 steroids, Xestokerols A-C, having a Cyclopropane ring on the side chain from an Okinawa sponge, Xestospongia sp.

Several reports describe isolations of new sulfated steroids with antimicrobial activity from several species of sponges. The compounds are Annasterol sulfate from the Pacific deep water sponge Poecillastra laminaris, ${ }^{11}$ Acanthosterol sulfates A-J from Acanthodendrilla sp, ${ }^{12}$ Topsentiasterol sulfate A-E from Topsentia $s p,{ }^{13}$ and echinoclasterol sulfate phenethyl ammonium salt from.

A highly oxygenated 9, 11-secosterol, stellettasterol, has been reported as a constituent of the sponge Stelletta $\mathrm{sp} .{ }^{14}$ Nitrogenous steroids or steroidal alkaloids are rather rare from marine sources. ${ }^{15}$ Reported a steroid/amino acid conjugate, polymastiamide A, from the Norwegian sponge Polymastia boletiformis. The marine environment, which contains a vast array of organisms with unique biological properties, is one of the most underutilized biological resources. To date, algae and microalgae are referenced in the literature as sources of bioactive compounds for use as functional food ingredients. ${ }^{16,17}$ In some of these matrices, interesting functional compounds were isolated previously. ${ }^{18-20}$

\section{Experimental section}

\section{Collection of sponges, sample preparation and extraction}

The sponges 22 species were collected from the low inter tidal pools at Bay of Bengal from Gulf of Manner Biosphere reserve of Tuticorin coast $\left(8^{\circ} 47 \phi \mathrm{N}, 78^{\circ} 8 \phi \mathrm{E}\right)$ and Rameswaram coast $\left(9^{\circ} 28 \notin \mathrm{N}, 79^{\circ} 12 \phi \mathrm{E}\right)$ at $4-5 \mathrm{~m}$ depth from Tamil Nadu, India. The sponges were collected by an eco-friendly bulk collection by catch in the fishing nets. From 
the all twenty one sponges identified, tissues samples were incised out and $(100 \mathrm{~g})$ were washed with sea water, air dried and chopped into small size before being ground into fine paste. Using the paste the Ethyl acetate (EtOAc) and Methanol $(\mathrm{MeOH})$ were carried out. The extraction was carried out in triplicates for $48 \mathrm{~h}$. The extract was stored in dark container and left in deep freezer at $-20^{\circ} \mathrm{C}$. After $48 \mathrm{~h}$ the extract was filtered through Whatman filter paper (No. 2) and concentrated using vacuum rotary evaporator (Super fit, Bangalore).

\section{Thin layer chromatography (TLC)}

Each fractions of the column eluted sample was subjected to TLC to find out a single compound in the fraction. TCL was performed on a prepared plates with Si-gel F254 grade (Merck, Darmstadt, Germany) as stationary phase. Liquid mobile phases were either semi polar $\left(\mathrm{CH}_{2} \mathrm{Cl}_{2}: \mathrm{MeOH} ; 9: 1, \mathrm{v} / \mathrm{v}\right)$ or non polar (Hexane:EtOAc;8:2,v/v). Reversed phase (RP) was used for polar fractions. A one-dimensional ascending development technique was used to detect the constituents of an extract on TLC plate. Visual detection was done in daylight and under UV light at a wave length of 254 and $344 \mathrm{~nm}$ depending on the group of compounds investigated.

\section{Column chromatography}

So sponges are the rich source of novel bioactive compounds. Hence in the present study the column chromatographically eluted 16th fraction of ethyl acetate extracts of Aurora globostellata was reported to exhibit a good antimicrobial and antiviral activity. Hence the eluted compound was crystallized and subjected to Nuclear Magnetic Resonance (NMR) analysis $\left({ }^{1} \mathrm{H}-\mathrm{NMR},{ }^{13} \mathrm{C}-\mathrm{NMR}\right.$, DEPT135, DOSY-NMR), High Resolution Mass Spectrum (HR-MS) Ultra Violet spectroscopy (UV), Infra Red spectroscopy (IR) and fluorescence spectroscopy studies to elucidate the structure of the compound isolated from this fraction of column eluted sample.

\section{Results and discussion}

\section{Hexane}

Ethyl acetate (8:2\%) fraction yielded a homogenous compound. It is a greenish yellow crystal, melting points 274 to 276 . It answered Liebermann and Burchard test and also Molisch test. It indicated that it may be steroidal glycosides. Elemental analysis indicated that Nitrogen (N) is present in the compound.

\section{In TLC Hexane}

Ethyl acetate $(60: 40)$, it gave a single pink colored spot. When methanolic sulfuric acid was sprayed and heated to $80^{\circ} \mathrm{C}$ in hot air oven for 5 minutes, the colour of the spot indicated the presence of Azasterol Glycoside.

\section{Hydrolysis}

Twenty five mg of compound was refluxed with $10 \mathrm{ml}$ of $2 \mathrm{~N} \mathrm{HCl}$ for 20 minutes. The condense were separated by separating funnel. $25 \mathrm{ml}$ ethyl acetate was added shaken well. Aglycone part is in ethyl acetate fraction. The mass spectral data of Aglycone confirmed the presence of Azasitosterol (m/z 429) and b-Sitosterol (m/z 414).

The aqueous layer after concentration was subjected to paper chromatographic analysis in Whatman No:1 filter paper with authentic sugars. The sugar moiety in the compound was identified as a disaccharide possibly b-D, Glucopyranosyl-glucopyranoside accounting the side chain mass spectrum of the compound $(\mathrm{m} / \mathrm{z}$ 803). This further confirmed the presence of the Azasterol glycoside
(Nitrogen substituted b- Sitosterol glycoside).The molecule formula of Aglycone part is $\mathrm{C}_{29} \mathrm{H}_{51} \mathrm{NO} . \mathrm{m} / \mathrm{z}$ peak 803 mass indicates the total part of compound structure. (Nuclear Magnetic Resonance (NMR) analysis ( ${ }^{1} \mathrm{H}-\mathrm{NMR}$ results Figure $1-5,{ }^{13} \mathrm{C}$-NMR, Figure 6, DEPT135, Figure 7 DOSY-NMR), High Resolution Mass Spectrum (HRMS) Ultra Violet spectroscopy (UV), Infra Red spectroscopy (IR) and fluorescence spectroscopy).

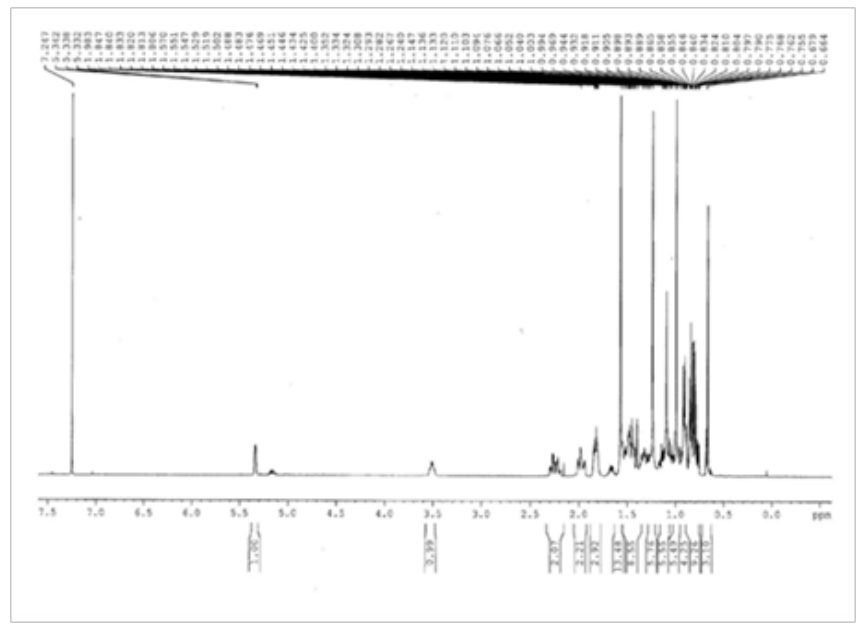

Figure I 'H-NMR spectra of purified compound I(Azasterol glycoside).

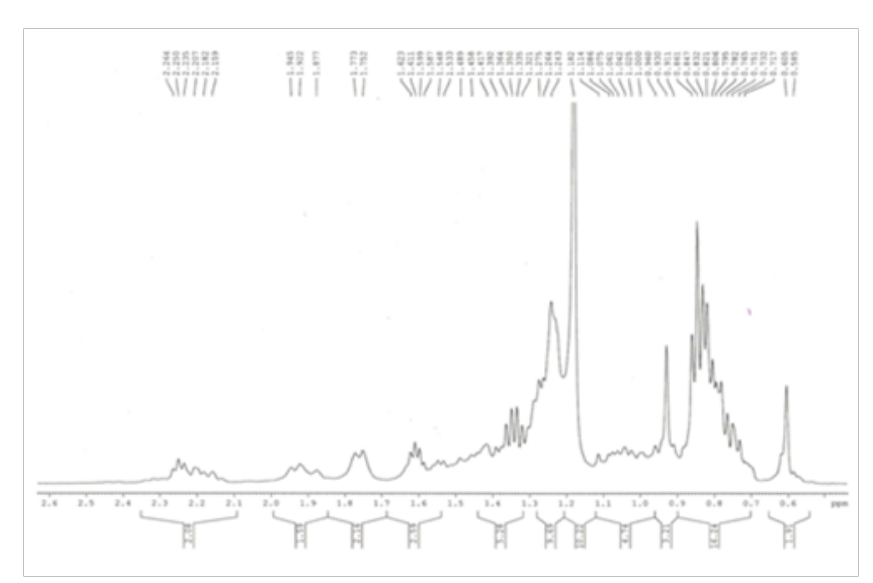

Figure 2 'H-NMR spectra of purified compound I(Azasterol glycoside).

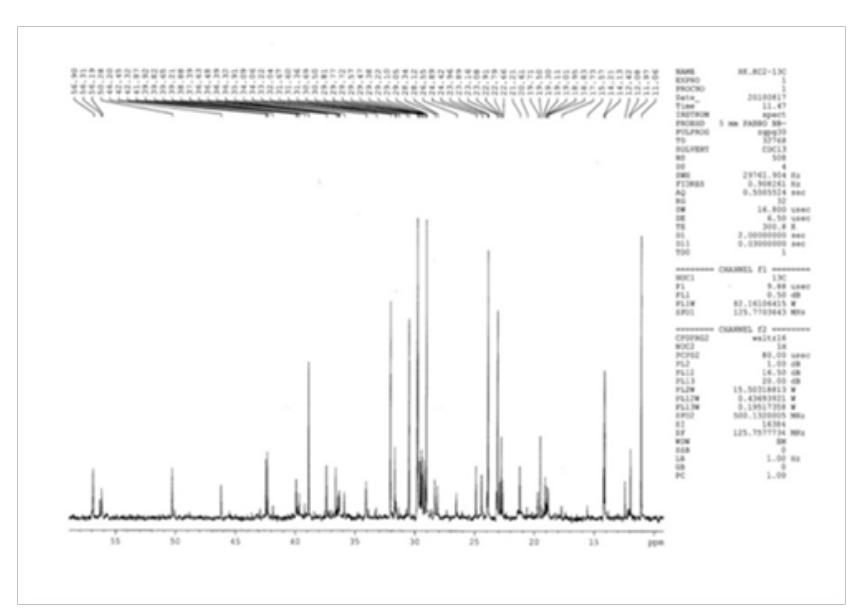

Figure $3{ }^{13}$ C-NMR spectra of purified compound I (Azasterol glycoside). 


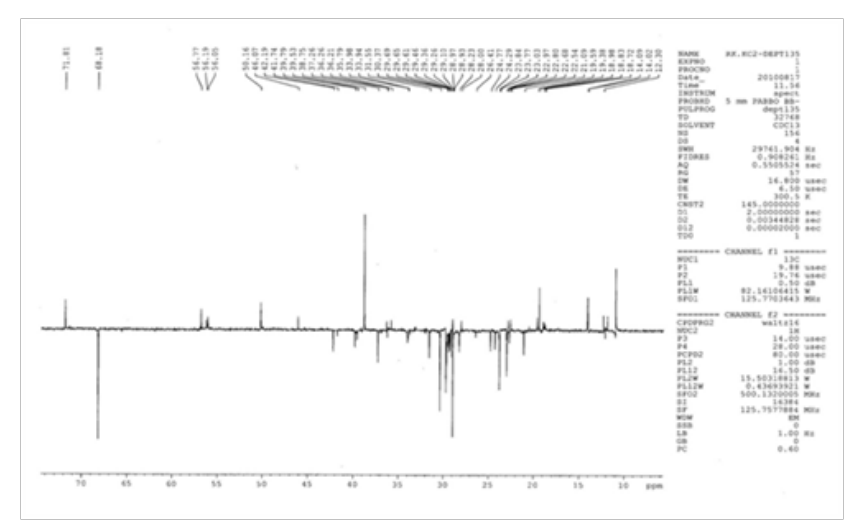

Figure 4 DEPT-I 35 spectra of purified compound I (Azasterol glycoside).

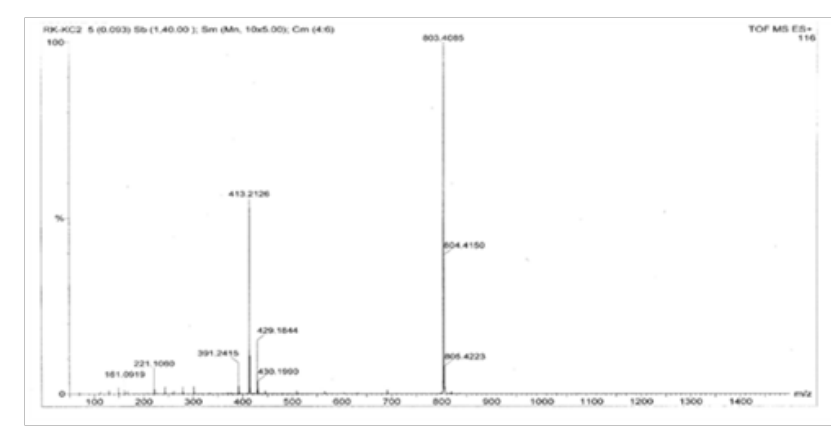

Figure 5 HR-MS spectra of purified compound I(Azasterol glycoside).

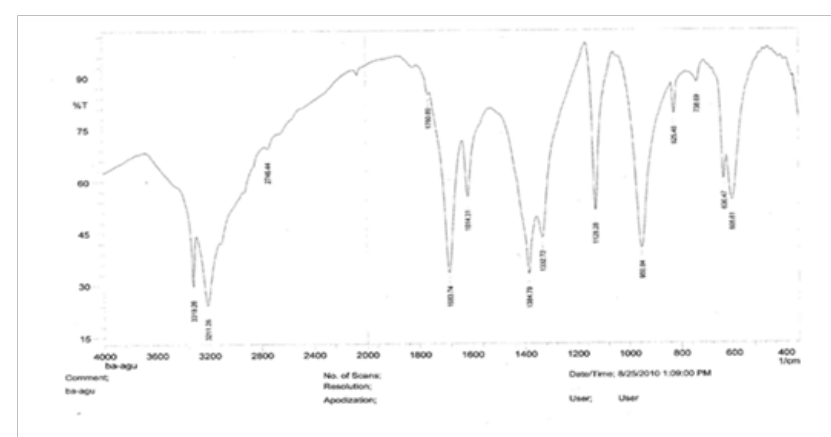

Figure 6 HR-MS spectra of purified compound I(Azasterol glycoside).

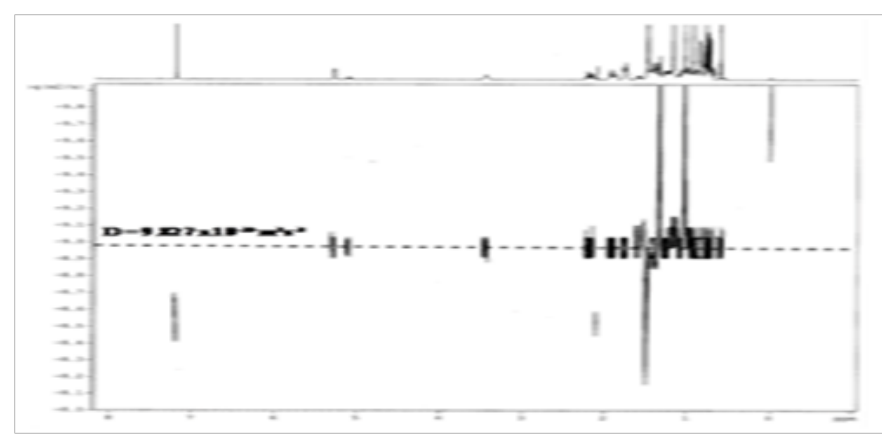

Figure 7 DOSY spectra.

\section{Aglycone part}

The mass spectra also indicated that the compound has Azasterol glycoside. The $\mathrm{m} / \mathrm{z} 414$ indicated that the Aglycone part of the compound was b-Sitosterol. The molecular weight of glycone part was 374 leading to a disaccharide attachment possibly b-D Glucopyronosyl-glucopyranoside (Figure 8).

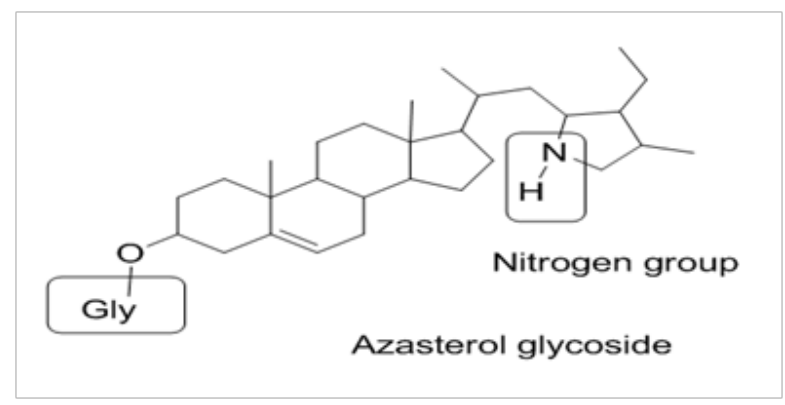

Figure 8 DOSY spectra.

\section{High resolution mass spectrum (HR-MS) (Figure 5)}

$\mathrm{M} / \mathrm{Z}$ peak at $803(\mathrm{M}+$ peak) Molecular ion peaks.

$\mathrm{M} / \mathrm{Z}$ peak at $804(\mathrm{M}+1$ peak) Molecular ion peaks with one proton abstracted from solvent, and again one peak found at $\mathrm{M} / \mathrm{Z}$ peak at 413 (Base peak - most stable peak).

\section{IR Spectrum (Figure 6)}

Peak at $2951=>$ aliphatic $\mathrm{CH}_{2}$ and $\mathrm{CH}_{3}$ groups

Peak at $1617=>\mathrm{C}=\mathrm{C}$ stretching and $\mathrm{N}-\mathrm{H}$ bending can give rise to a band about $1600 \mathrm{~cm}^{-1}$

Peak at $1268=>\mathrm{C}-\mathrm{C}$ stretching and $\mathrm{C}-\mathrm{N}$ - stretching can give rise to a band about $1260 \mathrm{~cm}^{-1}$

IR data suggest that the compound is accordance with a sterol derivative.

\section{Calculation of Hydrodynamic Radii}

Stoke-Einstein Equation $\mathrm{r}_{\mathrm{s}}=\frac{k T}{6 \pi \eta D}$

where $\mathrm{r}_{\mathrm{s}}$ is the hydrodynamic radii, $\mathrm{k}$ is the Boltzmann constant $\left(1.3807 \times 10^{-23} \mathrm{~m}^{2} \mathrm{Kgs}^{-2} \mathrm{~K}^{-1}\right), \mathrm{T}$ is the temperature $(298 \mathrm{~K}), \eta$ is the viscosity of the $\mathrm{CHCl}_{3}$ solvent $\left(5.8 \times 10^{-4} \mathrm{Kgm}^{-1} \mathrm{~s}^{-1}\right)$ and $\mathrm{D}$ is the diffusion co-efficient $\left(9.827 \times 10^{-10} \mathrm{~m}^{2} \mathrm{~s}^{-1}\right)$.

The average diffusion co-efficient of the compound 1, Azasterol glycoside is obtained from the DOSY-NMR studies. It is clearly evident from the DOSY spectra (Figure 7) that the isolated compound is pure and a single compound is separated from the extract. The contours corresponding to the ${ }^{1} \mathrm{H}-\mathrm{NMR}$ chemical shifts are along a same horizontal line indicates the existence of single compound in the solution. The hydrodynamic radii calculated using Stoke-Einstein equation is 3.8Á. (Figure 7) DOSY-NMR spectra of compound 1 in $\mathrm{CDCl} 3$ at $298 \mathrm{~K}$.

\section{UV-VIS and Fluorescence Studies}

(Figure 9) depicts the UV-VIS and fluorescence spectra of 
compound 1, Azasterol glycoside in Acetonitrile. The uv-vis spectra of compound 1 shows a maximum absorption at $275 \mathrm{~nm}$ which may be attributed to the $n-\pi^{*}$ or $\pi-\pi^{*}$ transition. A very dilute acetonitrile solution of compound 1 Azasterol glycoside upon excitation at $275 \mathrm{~nm}$ shows a strong fluorescence emission at $350 \mathrm{~nm}$ and excitation spectrum is the mirror image of the emission spectra. This study clearly reveals that the compound 1, Azasterol glycoside is highly fluorescent.

Figure 9 Depicts the uv-vis and fluorescence spectra of compound I.

(Figure 10) UV-VIS spectra of compound 1, Azasterol glycoside

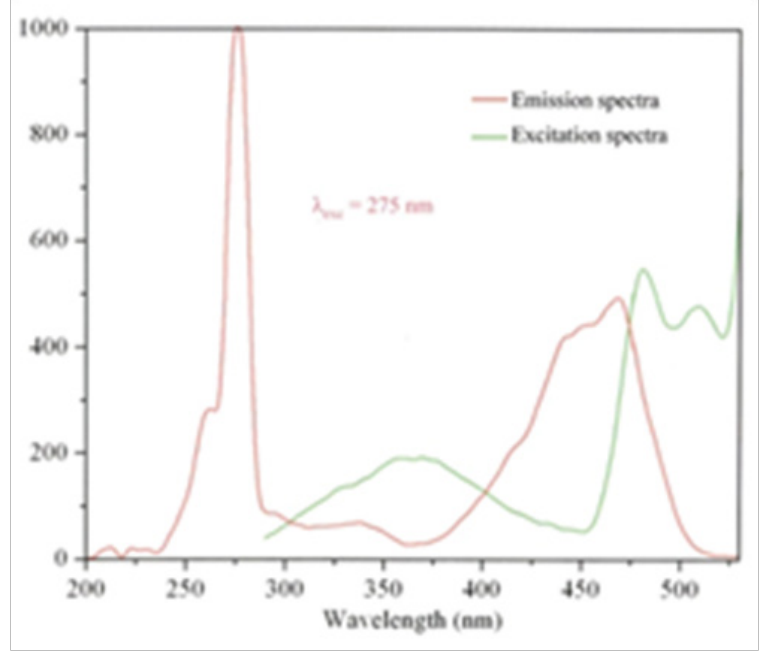

in acetonitrile solution and b) emission and excitation spectra of compound 1 in acetonitrile solution. $\lambda_{\text {exc }}=275 \mathrm{~nm}$, scan rate $=300 \mathrm{~nm} /$ min, excitation slit width $=8.0 \mathrm{~nm}$ and emission slit width $=8.0 \mathrm{~nm}$.

Figure 10 UV-VIS spectra of compound I.

The biological evaluation of marine derived extracts and pure

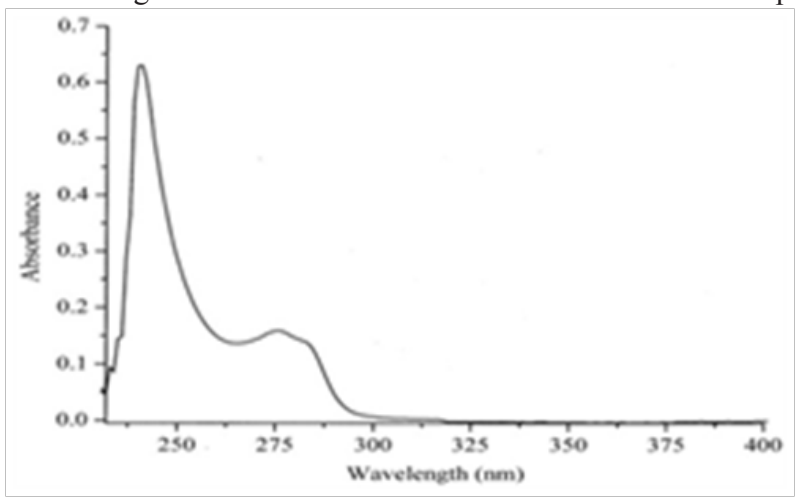

compounds for pharmaceutical development have been based on assays development from the libraries of the already developed synthetic compounds. Marine microbes as model systems offer the potential to understand and develop treatments of disease based on the normal physiological role of their secondary metabolites. For example, the mechanisms of toxin action are well-known and are currently being applied to the development of new drugs.

\section{Conclusion}

From the current study it could be noted down that a vast stretch of bioactive compounds present in the marine environment is still unexplored. The bioactive compound Azasterol glycoside from Aurora globostellata which were found to be bioactive compound. Also these active factors could be used to develop antimicrobial wound care finishes which could replace the commercial wound care agents, being cheaper in cost and effective in action.

\section{Acknowledgments}

Authors are thankful to Principal, Kamarajar Govt. Arts and Science College, Surandai, M.S.University, Tirunelveli- 627859 , Tamilnadu, India, lab facilities and encouragement. We thankful for supporting agency of University Grant Commission, Govt. of India, New Delhi.

\section{Conflicts of interest}

The author declares that there is no conflict of interest.

\section{References}

1. Lalli CM, Parson TR. Biological Oceanography. New York, USA. 1993:1-10.

2. Bergmann W, Freeney RJ. Contribution to the study of marine product of marine products. The nucleosides of sponges. I J org chem. 1951;16(16):981-987.

3. Fenical W. New pharmaceuticals from marine organism. Trends biotechnol. 1997;15(9):339-341.

4. Proksch PR, Edrada RA, Ebel R. Drugs from the seas-current status and microbiological implications Appl. Appl Microbial Biotechnol. 2002;59(2-3):125-134

5. Ireland CM, Copp BR, Forster MP, et al. Biomedical potential of marine natural product. In: Attaway D, Zaborsky OR, editors. Pharmaceutical and bioactive natural products. New York, USA: Marine biotechnology Plenum publishing Corp; 1993;1-43.

6. Hooper JNA, Van Soest RWM. The systema porifera-A Guide to the classification of sponges. New York: Kluwer Academic/Plenum publishers; 2002:1-1756.

7. Hoffmann H, Lindel T. Synthesis of the pyrrole-imidazole alkaloids. Synthesis. 2003;12:1753-1783.

8. Schmitz FJ. Uncommon marine steroids. Marine Natural Products, Chemical and Biological Perspectives. Academic Press. 1978;1:241297.

9. Ishibashi M, Yamagishi E, Kobayashi J. Topentinols A-J New sterols with highly branched side chains from marine sponge. Topsentia $\mathrm{sp}$ Chem Pharm Bull. 1997;45:1435-1438.

10. Kobayashi J, Cheng JF, Ishibashi M, et al. Two novel azetidine alkaloids with potent actomyosin ATPase activating activity from the Okinawan marine sponge. Penares sp. J Chem Soc Perkin Trans. 1991;1:11351138 .

11. Makarieva TN, Stonik VA, D’yachuk, et al. Annasterol sulfate, a novel marine sulfated steroid, inhibitor of glucanase activity from the deep water sponge Poecillastra laminaris. Tetrahedron Lett. 1995;36(1):129 132.

12. Tuskamoto S, Kawabata T, Kato H, et al. Naamidines 4 and 1 cytotoxic Imidazole Alkaloids from the Indonesia marine sponge Leucetta chagosensus. J Nat pro. 2007;52:4181-4186.

13. Fuestani N, Sugawara T, Matsunago S. Bioactive marine metabolites 41 Theopederins A-E, potent antitumor metabolites from a marine 
sponge Theonella sp. J Org Chem. 1992;57(14):3828-3832.

14. Li H, Matshunaga S, Fusetani N. A new 9,1-secosterol, stellettasterol from a marine sponge Stellatta sp. Experientia. 1994;50(8):771-773.

15. Kong F, Andersen RJ. Polymastimide A, a novel steroid/amino acid conjugate isolated from the Northwegian marine sponge Polymastia boletiformis (Lamarck 1815). J Org Chem. 1993;58(24):6924-6927.

16. Plaza M, Santoyo S, Jaime L, et al. Screening for bioactive compounds from algae. J Pharm Biomed Anal. 2010a;51(2):450-455.

17. Plaza M, Amigo-Benavent M, Castillo MD, et al. Facts about the formation of new antioxidants in natural samples after subcritical water extraction. Food Research International. 2010b;43(10):2341-2348.

18. Kadam SU, Prabhasankar P. Marine foods as functional ingredients in bakery and pasta products. Food Research International.
2010;43(8):1975-1980.

19. Kim SK, Wijesekara I. Development and biological activities of marine-derived bioactive peptides: a review. Journal of Functional Foods. 2010;2(1):1-9.

20. Parekh J, Chanda SV. In vitro antimicrobial activity and Phytochemical analysis of some Indian medicinal plants. Turk J Biol. 2007;31:53-58. 